\title{
Effect of alterations of dietary sodium on the severity of asthma in men
}

\author{
Oliver J Carey, Christopher Locke, John B Cookson
}

\begin{abstract}
Background-There is some evidence of a positive association between increased dietary salt consumption and both increased bronchial reactivity and mortality from asthma in men. This study assesses the effects of alterations in dietary salt consumption on the clinical severity of asthma in adult male asthmatic patients.
\end{abstract}

Methods-A randomised, double blind, placebo controlled, crossover design was employed. Twenty seven mild to moderate asthmatic patients were established on a low sodium diet $(80 \mathrm{mmol} / \mathrm{day})$ at the end of a 4-5 day run in period and then randomised to receive 200 mmol/day slow sodium or matching placebo for five weeks, crossing over to the alternative regime for a further five weeks. Patients used diary cards to record twice daily peak expiratory flow rates, daily symptom scores, and bronchodilator consumption. Spirometry and degree of bronchial responsiveness (methacholine challenge test) were measured at screening and at the end of each treatment period. Twenty four hour urinary sodium excretion was measured at screening and in duplicate for each treatment period.

Results-Twenty two patients completed the study. For these patients the mean (95\% confidence interval $(\mathrm{CI})$ ) difference in 24 hour sodium excretion between treatments was 204 (175 to 235) mmol. Compared with placebo, sodium supplementation resulted in deleterious alterations of all measured parameters. Bronchial reactivity rose on slow sodium with a $0.73(0.2$ to 1.3$)$ doubling dose methacholine difference compared with placebo. Estimated median ( $95 \% \mathrm{CI}$ ) difference in bronchodilator consumption was $1.3(0.4$ to $2 \cdot 1)$ puffis per day, the estimated median difference in symptom score was $0.6(0.2$ to 0.9$)$, and mean forced expiratory volume in one second fell by $0.21(0.05$ to 0.37$) 1$. The peak expiratory flow rate rose on placebo and fell on slow sodium. Median differences between treatments were $5 \cdot 6 \%(2 \cdot 2 \%$ to $9.8 \%)$ for morning and $7 \cdot 8 \%(3.9 \%$ to $12.9 \%)$ for evening peak expiratory flow rate.
Conclusions-Our results suggest that large increases in dietary sodium result in physiological deterioration and increased morbidity in male asthmatic patients.

(Thorax 1993;48:714-718)

There is a strong association between regional figures for mortality from asthma and purchases of table salt per person for adult men and children of both sexes (but not adult women) in England and Wales. ${ }^{1}$ The degree of bronchial responsiveness to histamine is positively correlated with the 24 hour urinary sodium excretion in men $^{2}$ and rises with increased dietary sodium. ${ }^{34}$ Severity of asthma correlates with the degree of bronchial responsiveness ${ }^{5}$ and it is therefore possible that the severity of asthma can be influenced by alterations in dietary sodium consumption. This study was designed to assess the effect of changes in dietary sodium on the severity of symptoms of asthma, bronchodilator requirements, lung function, and bronchial responsiveness to methacholine.

\section{Methods}

SUBJECTS

Twenty seven stable male asthmatic patients aged between 12 and 68 years were recruited o with consent from their general practitioners. All gave a history of intermittent wheeze, shortness of breath, and chest tightness relieved by bronchodilator therapy, had previously been given a diagnosis of asthma, and were taking asthma medication at the time of the study. Only one gave a history of smoking and he had stopped several years previously.

All were taking inhaled $\beta$ sympathomimetic agonists and 12 inhaled corticosteroids. Four were taking inhaled sodium cromoglycate and three oral theophyllines. No patient was using oral $\beta$ agonists, antihistamines, or steroids at the time of the study.

The patients gave written informed consent to the study which was approved by the local ethics committee.

\section{STUDY DESIGN}

A double blind randomised crossover design was used to compare sustained release 
sodium (slow sodium) with placebo in patients receiving a low sodium diet.

\section{Assessment}

Before entry subjects underwent clinical examination and blood was taken for routine haematological and biochemical analysis. Discretionary chest radiographs and electrocardiograms were performed. No subject was entered into the study who had a history of or clinical or laboratory evidence of renal, hepatic, cardiovascular disease, hypertension, or electrolyte imbalance, or who was taking diuretic therapy.

\section{Randomisation}

Paired treatment courses were assigned a unique number from 1 to 30 . Each number coded for placebo treatment crossing to slow sodium or vice versa was allocated by a random draw. At randomisation patients were consecutively assigned a treatment number starting at 1 .

\section{Protocol}

At the initial assessment a methacholine challenge test was performed (see below) and subjects were instructed in the use of a peak flow meter (mini-Wright) and diary card. After 4-5 days, during which patients recorded peak flow rates (PEF) and collected a 24 hour specimen of urine for sodium analysis, they were placed on a low sodium diet ( $80 \mathrm{mmol}$ supervised by a dietician) and randomised to receive either slow sodium (200 mmol daily in two doses) or matching placebo for five weeks, followed by the alternative regimen for a further five weeks. Subjects recorded morning and evening PEF (best of three) and completed the diary cards recording symptoms and bronchodilator consumption daily throughout the 10 week study period. Forced expiratory volume in one second $\left(\mathrm{FEV}_{1}\right.$, best of three) and methacholine challenge tests were performed at weeks 5 and 10 , and 24 hour urine samples were collected at weeks $3,5,8$, and 10 .

Subjects were asked to use inhaled bronchodilators on an "as required" rather than a regular basis and all other medication was kept constant during the study period. They were asked not to use Ventolin within four hours of PEF recordings where possible.

\section{Symptom scores}

Daily symptom scores were recorded on a scale from 0 to 5 where $0=$ no symptoms and $5=$ symptoms so severe that the patient either could not go to work or could not perform normal daily activities.

\section{Methacholine challenge tests}

Airway responsiveness to methacholine was measured by the method of Yan et al. ${ }^{6}$ Subjects were asked to avoid inhaled bronchodilators for six hours and oral theophyllines for at least 12 hours before the challenge tests. Baseline $\mathrm{FEV}_{1}$ was measured with a dry wedge spirometer (Vitalograph, Buckingham UK). Subjects then inhaled three puffs of saline from a DeVilbiss No 40 hand held nebuliser (delivering 0.0025-0.0035 ml per actuation) followed by incremental doubling doses of methacholine from $0.012 \mu \mathrm{mol}$ to a maximum of $12.24 \mu \mathrm{mol}$ or until a $20 \%$ fall in $\mathrm{FEV}_{1}$ from the maximum value after saline was recorded. Spirometry was repeated at one minute intervals after each dose.

All subsequent bronchial challenge tests on an individual subject were performed at the same time of day.

\section{4 hour urine specimens}

On receipt of specimens the volume was measured and concentrations of sodium and potassium were measured by ion specific electrodes. Creatinine was measured by a modified Jaffe rate reaction.

\section{ANALYSIS}

Comparisons between placebo and slow sodium were made for symptom scores, bronchodilator consumption, and PEF values using combined data for all daily recordings from the last 21 days of each treatment period. A two week washout period was effectively introduced by this strategy. Available data did not allow comparisons with pretrial baseline results for symptom scores and bronchodilator consumption.

Analysis of variance for repeated measures (SPSS) revealed a significant treatment/ period interaction for the paired PEF data. These data were therefore analysed as parallel groups for the first period only ( $n=11$ for both slow sodium and placebo). The percentage change of the mean of the 21 PEF recordings for individuals from their pretrial baseline value was analysed by the MannWhitney two sample test. Percentage change was used to provide a relative measure as the groups were not well matched at baseline. The pretrial values were taken as the mean of the four days' recordings before randomisation. PEF recordings made within four hours of using bronchodilator were omitted from analysis.

Between treatment comparisons of $\mathrm{FEV}_{1}$ and $\mathrm{PD}_{20}$ methacholine (dose of methacholine producing a $20 \%$ fall in $\mathrm{FEV}_{1}$ from the post saline value) were compared by the paired Student's $t$ test (after logarithmic transformation of reactivity data). The $\mathrm{PD}_{20}$ methacholine was calculated by linear interpolation on a plot of percentage fall in $\mathrm{FEV}_{1}$ from the post saline value against the dose of methacholine on a logarithmic scale.

Creatinine excretion was used to assess the completeness of 24 hour urine samples, those showing excretion relative to body mass outside the laboratory reference range being excluded from analysis.

With the exception of the peak flow data our analyses detected no significant period or sequence of treatment effects or interactions. ${ }^{7}$

\section{Results}

Twenty two subjects of mean age 36 (range 12-68) years completed the study. Five were 
Changes in sodium excretion, lung function, reactivity, symptoms, and bronchodilator consumption

\begin{tabular}{|c|c|c|c|}
\hline Measurement & $\begin{array}{l}\text { Baseline } \\
(n=22)\end{array}$ & $\begin{array}{l}\text { Low sodium diet } \\
+ \text { slow sodium } \\
(n=22)\end{array}$ & $\begin{array}{l}\text { Low sodium diet } \\
+ \text { placebo } \\
(n=22)\end{array}$ \\
\hline $\begin{array}{l}\text { Mean (SD) } 24 \text { hour } \\
\text { urinary sodium } \\
\text { excretion (mmol) }\end{array}$ & $159(42)$ & $292(68)$ & $88(31)^{\star \star \star \star}$ \\
\hline Mean (SD) $\mathrm{FEV}_{1}(\mathrm{l})$ & $2 \cdot 68(1 \cdot 2)$ & $2 \cdot 61(1 \cdot 2)$ & $2 \cdot 82(1 \cdot 2)^{\star}$ \\
\hline $\begin{array}{l}\text { Geometric mean } \\
\mathrm{PD}_{20}(\mu \mathrm{mol}) \text { (range) }\end{array}$ & $0.53(0.05-7.00)$ & $0.39(0.03-9.00)$ & $0.65(0.05-6.20)^{\star}$ \\
\hline $\begin{array}{l}\text { Median daily } \\
\text { symptom score (25th } \\
\text { to } 75 \text { th percentiles) }\end{array}$ & - & $2.0(1.5$ to 2.9$)$ & $1.5(0.7 \text { to } 2 \cdot 0)^{\star \star}$ \\
\hline $\begin{array}{l}\text { Median puffs per day } \\
\text { of bronchodilator } \\
\text { ( } 25 \text { th to } 75 \text { th percentiles) }\end{array}$ & - & $5.9(3.9$ to 8.3$)$ & $5.0(3.6 \text { to } 7 \cdot 3)^{\star \star}$ \\
\hline
\end{tabular}

FEV 1 - forced expiratory volume in one second; $\mathrm{PD}_{20}$-dose of methacholine producing a $20 \%$ fall in $\mathrm{FEV}_{1} ;{ }^{\star} \mathrm{p}<0.05 ;{ }^{\star \star} \mathrm{p}<0.01 ;{ }^{\star \star \star \star} \mathrm{p}<0.0001$ for differences between slow sodium and placebo. fell on slow sodium by $0.07(-0.22$ to 0.07$) 1$ $(2 \cdot 6 \%)(\mathrm{p}>0 \cdot 1)$.

PEF

Changes in PEF over time by treatment group for the first period are shown in the figure. PEF rose on placebo and fell on slow sodium. The results according to the planned analysis of combined data for weeks 3-5 are set out below.

Morning PEF: the mean (SD) morning PEF on placebo $(n=11)$ rose from 352 (111) $1 / \mathrm{min}$ at baseline to 361.5 (112) $1 / \mathrm{min}$. The mean morning PEF for the slow sodium group $(n=11)$ fell from 434 (126) $1 / \mathrm{min}$ at baseline to $419(116) \mathrm{l} / \mathrm{min}$. In terms of percentage change from baseline the placebo group showed a median (25th to 75 th percentiles) increase of $2.6 \%(-3.0 \%$ to $6 \cdot 1 \%)$ compared with a fall of $3.2 \%(-6.7 \%$ to $0.6 \%$ ) for the slow sodium group. The median $(95 \% \mathrm{CI})$ difference between treatments was $5.6 \%(2 \cdot 2 \%$ to $9.8 \%)(p<0.05)$.

Evening PEF: the mean (SD) evening PEF on placebo rose from 396 (115) $1 / \mathrm{min}$ at baseline to $420(117) 1 / \mathrm{min}$. The slow sodium group showed a fall from 452 (135) $1 / \mathrm{min}$ at baseline to $439(133) \mathrm{l} / \mathrm{min}$. The median (25th to 75th percentiles) percentage changes from baseline were thus $+4.0 \% \quad(1.6 \%$ to $8.4 \%)$ for placebo and $-4.5 \%(-4.8 \%$ to $0.9 \%)$ for slow sodium. The median $(95 \%$ CI) difference was $7 \cdot 8 \%(3.9 \%$ to $12.9 \%)$ $(\mathrm{p}<0.01)$.

\section{BRONCHODILATOR CONSUMPTION AND}

SYMPTOM SCORE

Overall there was an estimated median (95\% CI) reduction in bronchodilator consumption of $1.3(0.4$ to $2 \cdot 1)$ puffs per day $(\mathrm{p}<0.01)$ for placebo compared with slow sodium. Correspondingly, in comparison with slow sodium there was a decrease in estimated median symptom score on placebo of $0.6(0.2$ to 0.9$)(\mathrm{p}<0.01)$. line, mean $\mathrm{FEV}_{1}$ rose on placebo by 0.14 $(95 \%$ CI 0.03 to 0.25$) 1(5 \%)(p<0.05)$ and

Mean (SD) peak expiratory flow rate (PEF) by study week ( \pm one day) in $(A)$ morning and $(B)$ evening. ${ }^{*} p<0.05$ and $\star_{*} p<0.01$ for differences between sodium and placebo (\% change from baseline). $\square$, placebo; $\bigcirc$, sodium.

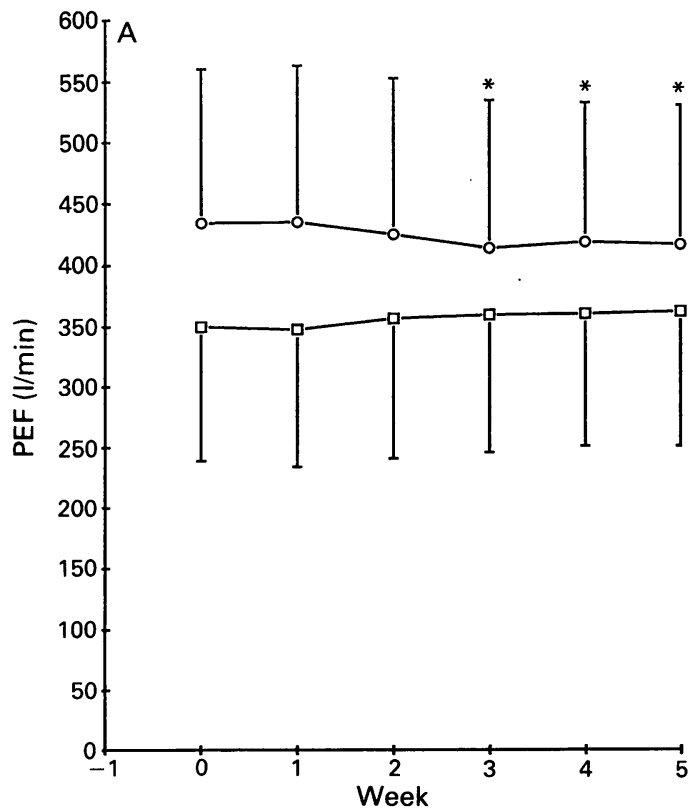

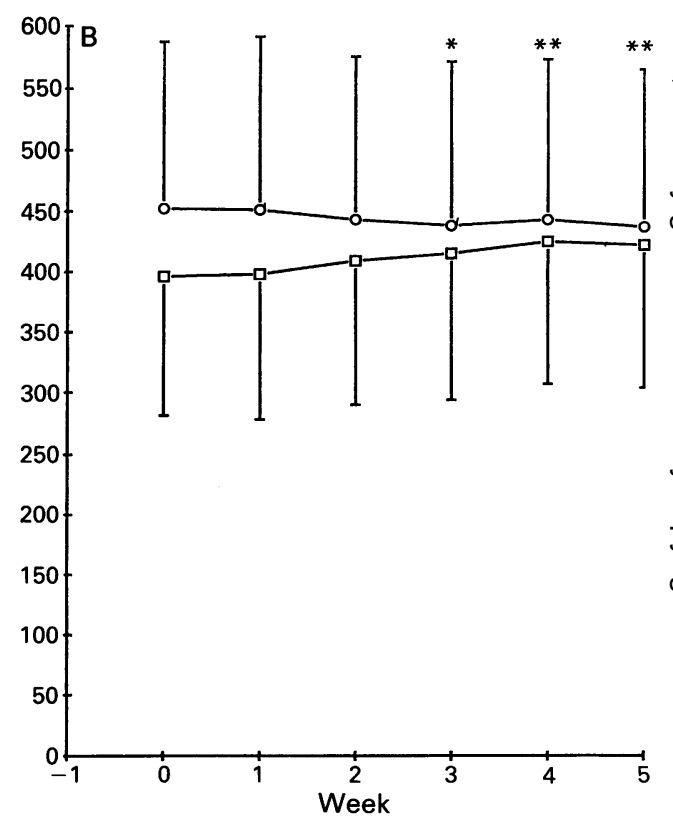


BRONCHIAL REACTIVITY

Geometric mean (range) $\mathrm{PD}_{20}$ was 0.53 $(0.05-7.00) \mu \mathrm{mol}$ at baseline. This fell on slow sodium to $0.39(0.03-9.00) \mu \mathrm{mol}$ and rose on placebo to $0.65(0.05-6 \cdot 20) \mu \mathrm{mol}$. The difference between slow sodium and placebo was equivalent to $0.73(95 \%$ CI 0.2 to $1 \cdot 3$ ) doubling doses methacholine.

\section{Discussion}

Recent epidemiological evidence indicates an association between mortality from asthma and high dietary sodium intake. ${ }^{1}$ Subsequent experiments have shown that bronchial reactivity is increased on high sodium diets. ${ }^{34}$ This evidence is clearer for men than for women as it is for the relationship between sodium and hypertension. For this reason we confined our study to male asthmatic patients.

A change from a high sodium to a low sodium intake resulted in reduced bronchial reactivity, bronchodilator requirements, and symptoms, with concurrent improvement in lung function. The daily PEF recordings suggest that most of the effects occurred in weeks 2 and 3 after dietary change. There were little or no additional effects observed beyond the third week. The changes in PEF were sustained to week 5 indicating no tendency toward tolerance.

Our study was not strictly designed to assess the effect of reductions of dietary sodium from normal ranges and we lack useful baseline data on bronchodilator consumption and symptom scores. Initiation of a low sodium diet was likely to affect dietary factors in addition to sodium. In order to make relatively unconfounded comparisons between baseline and the two treatment periods, a prolonged single blind run in period would have been necessary. Such a protraction may have jeopardised the study because of a fall off in compliance or greater loss of subjects.

Comparisons with baseline data should be made with caution for these reasons, and the possible effects of unblinded patient/observer assessment bias and modification of patient behaviour on entry to a research study-for example, increased compliance with usual therapy.

Notwithstanding these potential problems, comparisons between baseline and the low and high sodium treatments suggest a continuous dose-response effect. Although the magnitude of the improvements with a low sodium diet (placebo) compared with sodium supplement may be clinically useful, the changes in peak flow, $\mathrm{FEV}_{1}$ and bronchial reactivity from baseline to placebo were modest. The changes observed for these parameters were less than would be expected for seasonal alterations ${ }^{8}$ and low dose budesonide treatment. ${ }^{9}$ These results indicate that sodium restriction as a therapeutic intervention may only be of use in asthmatic patients with high daily sodium intakes. The normal range of daily sodium excretion for British adults is $100-250 \mathrm{mmol}^{10}$ The probable degree of sodium restriction necessary to achieve a useful response, and the limited number of asthmatic subjects for whom such restriction would be appropriate or tolerated further, lessens the therapeutic usefulness of sodium restriction.

Our findings do not agree with those of Lieberman and Heimer ${ }^{11}$ who found no change in PEF with alterations in dietary sodium in an open crossover study. Their negative findings may be explained by differences in study design and patient selection. Their treatment periods were considerably shorter and no washout intervals were included between treatments. The changes in sodium intake were smaller than in our study. Fewer patients were studied and half were women who, previous work would suggest, are less likely to show a response. No other measures of asthma were assessed which may have helped to qualify the findings in PEF.

The mechanism of the effect of dietary sodium on bronchial reactivity is unknown. Animal experiments have shown that the hyperreactivity of sensitised bronchial smooth muscle is associated with an exaggerated influx of sodium across the cell membranes. ${ }^{12}$ It is possible that this inhibits the exchange mechanism of sodium and calcium ions ${ }^{13}$ resulting in raised intracellular calcium and thus increased contractility. High sodium consumption may enhance this abnormality. High sodium intake has been shown to inhibit $\mathrm{Na}^{+} / \mathrm{K}^{+}$ATPase in erythrocytes of normotensive males. ${ }^{14}$ The resulting inhibition of the $\mathrm{Na}^{+} / \mathrm{K}^{+}$pump would be expected to increase levels of intracellular sodium and, in turn, to increase intracellular calcium via inhibition of $\mathrm{Na}^{+} / \mathrm{Ca}^{++}$exchange. Increased airway smooth muscle contractility with pump inhibition is supported by animal experiments, ${ }^{1516}$ but has not been shown in studies in human subjects. ${ }^{17}$

Intracellular calcium concentrations influence aspects of inflammatory cell functions. ${ }^{18}$ High calcium levels would tend to result in hyperexcitability providing an alternative or additional speculative explanation for physiological deterioration in asthmatic subjects as the result of increased sodium loads.

The mechanism of $\mathrm{Na}^{+} / \mathrm{K}^{+}$ATPase inhibition is unclear and may be due directly or indirectly to hormonal or chemical changes associated with increased sodium loads, or to changes in physical properties of cell membranes with intravascular volume expansion. Plasma sodium levels change little with alterations in intake. It is therefore unlikely that the effects observed are due to the direct effects of sodium.

The association between dietary salt and asthma may help to explain geographical variations in the prevalence of asthma and the rise in prevalence in underdeveloped populations as they adopt a western lifestyle. ${ }^{19}$ While research continues to unravel the mechanisms of physiological changes due to alterations in dietary sodium, further long term and dose-response studies are needed to assess the usefulness of sodium restriction in both sexes. 
We gratefully acknowledge the help of Gary Young and Andrea Thompson, Department of Dietetics, Glenfield General Hospital for their help in organisation and supervision of the low sodium diets; John Beckett, Department of Statistics, Leicester University for statistical advice; and Ciba Geigy for the provision of the treatment preparations used in this study.

1 Burney PGJ. A diet rich in sodium may potentiate asthma: epidemiological evidence for a new hypothesis. Chest 1987;91:143-8S.

2 Burney PGJ, Britton JR, Chinn S, Tattersfield AE, Plat HS, Papacosta AO, et al. Response to inhaled histamine and 24 hour sodium excretion. $B M \mathcal{F}$ 1986;292:1483-6.

3 Burney PGJ, Neild JE, Twort CHC, Chinn S, Jones TD, Mitchell WD, et al. Effect of changing dietary sodium on the airway response to histamine. Thorax 1989;44: $36-41$.

4 Javaid A, Cushley MJ, Bone MF. Effect of dietary salt on bronchial reactivity to histamine in asthma. BMF 1988 297:454.

5 Juniper EF, Frith PA, Hargreaves FE. Airways responsiveness to histamine and methacholine: relationship to minimum treatment to control symptoms of asthma Thorax 1981;36:575-9.

6 Yan K, Salome C, Woolcock AJ. Rapid method for measurement of bronchial responsiveness. Thorax 1983;38 760-5.

7 Hills M, Armitage P. The two-period cross-over clinical trial. Br $\mathcal{F}$ Clin Pharmacol 1979;8:7-20.

8 Britton J, Chinn S, Burney P, Papacosta AO, Tattersfield A. Seasonal variation in bronchial reactivity in a community population. $f$ Allergy Clin Immunol 1988;82: 134-9.
9 Kraan J, Koeter GH, Vd Mark THW, Sluiter HJ, DeVries $\mathrm{K}$. Changes in bronchial hyperreactivity induced by 4 weeks of treatment with anti-asthmatic drugs in patients with allergic asthma: A comparison between budesonide and terbutaline. 7 Allergy Clin Immunol 1985;76:628-36.

10 Giles AM, Ross BD. Normal reference values for biochemical data. In: Weatherall DJ, Ledingham JGG, Warrell DA, Oxford textbook of medicine, Vol 2. New York; Oxford University Press, 1983:27.7.

11 Lieberman D, Heimer D. Effect of dietary sodium on the severity of bronchial asthma. Thorax 1992;47:360-3.

12 Souhrada M, Souhrada JF. Sensitisation induced sodium influxes in airway smooth muscle cells. Am Rev Respir Dis 1985;131:A356.

13 Blaustein MP. Sodium ions, calcium ions, blood pressure regulation, and hypertension: a reassessment and a hypothesis. Am f Physiol 1977;232:C165-73.

14 Weissberg PL, West MJ, Kendall MJ, Ingram M, Woods $\mathrm{KL}$. Effect of changes in dietary sodium and potassium on blood pressure and cellular electrolyte handling in young normotensive subjects. F Hypertension 1985;3: 475-80.

15 Bullock CG, Fettes JJF, Kirkpatrick CT. Tracheal smooth muscle: second thoughts on sodium-calcium exchange. f Physiol 1981;318:46P.

16 Agrawal KP, Hyatt RE. Airway response to inhaled ouabain and histamine in conscious guinea pigs. $f \mathrm{Appl}$ Physiol 1986;60:2089-93.

17 Knox AJ, Tattersfield AE, Britton JR. The effect of inhaled ouabain on bronchial reactivity to histamine in man. Br $\mathcal{F}$ Clin Pharmacol 1988;25:758-60.

18 Middleton E Jr. Calcium antagonists and asthma. 7 Allergy Clin Immunol 1985;76:341-6.

19 Burney PGJ. The causes of asthma-does salt potentiate bronchial reactivity? $\mathcal{f} R$ Soc Med 1987;80:364-7. 